\title{
Risk factors for metabolic bone disease among preterm infants less than 32 weeks gestation with Bronchopulmonary dysplasia
}

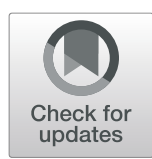

Wenwen Chen*, Zhenhai Zhang, Shuzhen Dai and Liping Xu* (1)

\begin{abstract}
Background: Bronchopulmonary dysplasia (BPD) infants present an increased incidence of metabolic bone disease $(M B D)$, but it is unknown which factors contribute to this. The aim of this study was to determine the risk factors for developing MBD in BPD infants.

Methods: A retrospective review of the medical records of BPD infants admitted to the Neonatal intensive care unit at Zhangzhou Hospital between Jun 2016 and May 2020 was performed. BPD infants with MBD were identified, two contemporaneous without MBD matched by gestational age and gender were randomly selected as controls for each case of MBD. The association between putative risk factors and MBD was estimated with ORs and 95\% Cls. A $P$-value threshold $\leq 0.2$ was used in univariate analysis for inclusion into a multivariate (adjusted) model with a $P$-value of $<0.05$ as statistically significant.

Results: A total of 156 BPD infants were enrolled with 52 cases of MBD and 104 controls. Fetal growth restriction (OR 6.00, 95\% Cl, 1.81-19.84), extremely low birth weight (OR 3.10,95\% Cl, 1.07-8.94), feeding volume $<80 \mathrm{~mL} / \mathrm{kg} / \mathrm{d}$ at the end of the 4th week after birth (OR 14.98, 95\% Cl, 4.04-55.58), cholestasis (OR 4.44, 95\% Cl, 1.59-12.40), late onset sepsis (OR 3.95, 95\% Cl, 1.12-13.98) and prolonged (> 2 weeks) diuretics application (OR 5.45, 95\% Cl, 1.2523.84) were found to be statistically significant risk factors for MBD in BPD infants.

Conclusion: In BPD infants of homogeneous gestational age, fetal growth restriction, extremely low birth weight, feeding volume $<80 \mathrm{~mL} / \mathrm{kg} / \mathrm{d}$ at the end of the 4th week after birth, cholestasis and late onset sepsis are significant risk factors for MBD. These findings provide potential predictive factors for MBD in BPD infants and warrant prospective validation.
\end{abstract}

Keywords: Metabolic bone disease, Bronchopulmonary dysplasia, Preterm, Risk factors

\section{Background}

Metabolic bone disease (MBD), characterized by low bone mass and demineralization of bone tissue, affects approximately $16-40 \%$ of very low birth weight (VLBW, birth weight $<1500 \mathrm{~g}$ ) and extremely low birth weight (ELBW, birth weight $<1000 \mathrm{~g}$ ) infants [1]. The exact incidence of MBD varied in different centers from a lack

\footnotetext{
*Correspondence: pipixiu@163.com; zzsyxlp@163.com Zhangzhou Hospital Affiliated to Fujian Medical University, Shengli W Rd, Xiangcheng District, Zhangzhou, Fujian, China
}

of consensus on the definition of MBD. MBD poses a consequent increase in bone fragility, contributing to long-term reduced linear growth. As MBD advances, rachitic changes and/or fractures are frequently observed. The understanding of MBD has grown in recent years, along with other preterm comorbidities. It has been reported that infants with bronchopulmonary dysplasia (BPD) have a higher incidence of MBD [2]. Among infants with birth weight $<1500 \mathrm{~g}$ suffered from severe BPD, about one third developed severe MBD [3].

(c) The Author(s). 2021 Open Access This article is licensed under a Creative Commons Attribution 4.0 International License, which permits use, sharing, adaptation, distribution and reproduction in any medium or format, as long as you give appropriate credit to the original author(s) and the source, provide a link to the Creative Commons licence, and indicate if changes were made. The images or other third party material in this article are included in the article's Creative Commons licence, unless indicated otherwise in a credit line to the material. If material is not included in the article's Creative Commons licence and your intended use is not permitted by statutory regulation or exceeds the permitted use, you will need to obtain permission directly from the copyright holder. To view a copy of this licence, visit http://creativecommons.org/licenses/by/4.0/ The Creative Commons Public Domain Dedication waiver (http://creativecommons.org/publicdomain/zero/1.0/) applies to the data made available in this article, unless otherwise stated in a credit line to the data. 
Several factors contributed to MBD had been identified. Costa $\mathrm{R}$ et al. found that the majority of MBD infants were male and presented lower gestational age, lower birth weight, and prolonged duration of parenteral nutrition [4]. Chen W et al. found that lower gestational age $(<30$ weeks), vitamin D supplementation at $>14$ days of age, and achievement of total enteral nutrition (TEN) beyond 28 days of age were independent risk factors for MBD in infants < 34 weeks gestational age [5]. Montaner Ramón A et al. found that only restricted fetal growth was independently associated with the development of severe MBD (OR 9.65, 95\% CI 3.48-26.76) in infants < 32 weeks gestational age and/or weight $<1500 \mathrm{~g}$ [6]. Ukarapong $\mathrm{S}$ et al. found that only cholestasis remained significantly risk factors (OR 9.6, 95\% CI 2.1-45.3) in infants $<30$ weeks gestational age and/or weight $<1,000 \mathrm{~g}$ [7]. Although BPD infants presented an increased risk for developing MBD, previous studies did not evaluate the risk factors that would be associated with MBD in BPD infants. On the other hand, some risk factors for MBD might become not obvious in infants with BPD since demographic and complications could be more homogeneous.

The present study was designed with the objective of knowing the risk factors for MBD in infants with BPD. These risk factors will help to identify high-risk individuals and propose recommendations for the prevention of MBD.

\section{Methods}

\section{Study population and setting}

The study was conducted in Zhangzhou Hospital with retrospective review of the electronic medical recordderived data of BPD infants who admitted to the Neonatal intensive care unit (NICU) between Jun 2016 and May 2020. The protocol was approved by the Institutional Ethical Committee of the hospital, with waiver of informed consent. BPD infants with MBD were identified as case group. Inclusion criteria consisted of the following: (1) gestational age $<32$ weeks, (2) survival up to 36 weeks post-menstrual age (PMA), (3) diagnosis of BPD according to National Institutes of Health that defined as requirement of oxygen support $(>21 \%)$ for at least 28 days and a subsequent assessment at 36 weeks PMA or discharge, whichever comes first. At the time of assessment, infants with no oxygen requirement were classified as having mild BPD, infants requiring $<30 \%$ oxygen were classified as having moderate BPD and infants with a need for positive pressure ventilation/continuous positive pressure and/or oxygen requirement $\geq 30 \%$ were classified as having severe BPD [8], and (4) diagnosis of MBD that defined as peak serum alkaline phosphatase (ALP) higher than $900 \mathrm{U} / \mathrm{L}$ and serum phosphorus ower than $1.8 \mathrm{mmol} / \mathrm{L}$, which yielded a sensitivity of $100 \%$ at a specificity of $70 \%$, with or without radiographic changes of long bones [9]. Exclusion criteria included: (1) gestational age $\geq 32$ weeks, (2) presence of significant congenital anomalies, including malformations of the digestive tract, (3) death before 36 weeks PMA. In our unit, mortality of infants with gestational age $<32$ weeks after 36 weeks PMA was $3.2 \%$. The incidence of MBD among BPD infants was $11.8 \%$. For each MBD case, two contemporaneous with BPD but without MBD matched at equivalent gestational age and gender (male: female $=1: 1$ ) were randomly selected as controls. The retrospective nature of the study predetermines the actual sample size.

Clinical data on demographics and putative risk factors for MBD were collected, including birth weight, gender, use of antenatal steroids, histologic chorioamnionitis (HCA), fetal growth restriction (FGR), maternal hypertensive disorders without FGR, prolonged rupture of membranes (PROM), type of feeding, initiation of oral vitamin D supplementation, feeding volume at the end of the 4th week after birth, necrotizing enterocolitis (NEC), patent ductus arteriosus (PDA), cholestasis, late onset sepsis (LOS), postnatal dexamethasone, diuretics application, fluid restriction, mechanical ventilation, thyroid function tests and platelet (PLT) count.

FGR was defined as antenatal diagnosis by any 2 of the following: estimated fetal weight below the 10th percentile according to the care provider reference curve, abnormal fetal Doppler findings, growth arrest, or maternal hypertensive disorders [10]. PROM was defined as rupture of the membranes occurring earlier than $24 \mathrm{~h}$ before delivery [10]. HCA was defined as the infiltration of neutrophils in any of the following structures: placental disc, the chorioamniotic membranes, and the umbilical cord [10]. Cholestasis was defined as direct bilirubin $>2 \mathrm{mg} / \mathrm{dL}$ [11]. Maternal hypertensive disorder was defined as systolic blood pressure $\geq 140 \mathrm{mmHg}$ and (or) diastolic blood pressure $\geq 90 \mathrm{mmHg}$ [12]. NEC was diagnosed according to revised Bell staging criteria. PDA was diagnosed with echocardiography confirmation beyond 3 days after birth. Hemodynamically significant PDA (hsPDA) was defined as a duct size $>1.5 \mathrm{~mm}$ and a left atrium-to-aortic root (LA:Ao) $>1.5$ and/or left-toright shunting of blood, or end-diastolic reversal of the blood flow in the aorta [13]. Thyroid-stimulating hormone $>10 \mathrm{mU} / \mathrm{L}$ was used as the cut-off level for hypothyroidism [14] and PLT $<100 \times 10^{\wedge} 9 / \mathrm{L}$ was considered to be thrombocytopenia [15]. LOS was diagnosed with clinical suspicion and evaluated by microbial culture or two non-specific blood indicators occurring after $72 \mathrm{~h}$ of birth [16].

In our NICU, we started parenteral nutrition within the first hours after birth and introduced enteral feeding with breast milk as soon as the infant reached a 
tolerated respiratory rate without hemodynamic instability. The feeding amount increased gradually with a rate of $20-30 \mathrm{~mL} / \mathrm{kg} / \mathrm{d}$ without signs of feeding intolerance. Oral vitamin D (800-1000 IU/d) supplementation was started when the feeding amount reaches $50 \mathrm{~mL} / \mathrm{kg} / \mathrm{d}$, and human milk fortification was added when the feeding amount of breast milk reaches $80 \mathrm{~mL} / \mathrm{kg} / \mathrm{d}$. Premature formula was also used if the amount of breast milk was insufficient. During hospitalization period, starting from the 2nd day after birth, while maintaining parenteral nutrition, serum calcium, phosphorus and ALP were measured weekly, and changed to twice a week after the establishment of TEN.

Regarding postnatal diuretics application, loop diuretics (furosemide) was administrated occasionally when intake volume exceeded output remarkably. Fluid restriction (total fluid volume $<140 \mathrm{~mL} / \mathrm{kg}$ beyond 2 weeks after birth) was introduced when there was pulmonary edema on chest radiographs. Furosemide (or hydrochlorothiazide) and spironolactone were applied when pulmonary edema was still obvious after fluid restriction. Diuretics at any type (including single dose and multiple doses) and prolonged duration (> 2 weeks) were analyzed differently.

\section{Statistical analyses}

Data were analyzed using SPSS version 26 and GraphPad Prism version 8 software. Descriptive data were presented as means \pm SD or medians (IQR) or percentages. Dichotomous or categorical variables were compared between cases and controls with the use of the $x^{2}$ analysis or Fisher exact test or z-test. Continuous variables were compared between groups via the two-sample t-test or Mann-Whitney $U$ test. A risk model was derived via logistic regression, with 95\% CIs calculated for ORs using the forced entry method. A $P$-value of $\leq 0.2$ was used in univariate analysis for inclusion of putative risk factors into the multivariate (adjusted) model. A $P$-value of < 0.05 was considered statistically significant.

\section{Results}

A total of 156 infants with BPD were enrolled in the study, with 52 cases of MBD and 104 controls. Radiographic changes including loss of metaphyseal sclerotic line, thinning of diaphyseal cortical, osteopenia, splaying, fraying, cupping or coarse trabecular pattern of metaphyses were found in $30.8 \%$ (16/52) of the MBD infants, while none of the controls showed apparente radiographic abnormalities. Gestational age was similar among the two groups (MBD $28.5 \pm 1.6 \mathrm{w}$ vs controls $28.5 \pm 1.6 \mathrm{w}, P=0.915)$. MBD infants had a lower birth weight (MBD $1051 \pm 186 \mathrm{~g}$ vs controls $1207 \pm 221 \mathrm{~g}, P<$ $0.001)$ compared with controls. There was no significant difference between the two groups in the distribution of
BPD severity (mild BPD 59.6\% vs. $70.2 \%$; moderate BPD $23.1 \%$ vs $21.2 \%$; severe BPD $17.3 \%$ vs $8.7 \%$ in MBD infants and controls respectively; $P=0.236$ ). Baseline serum calcium was lower in MBD infants, while baseline serum phosphorus did not show significantly difference (shown in Fig. 1 and 2. Figure note: Figure 1 Serum calcium concentration by weeks of life. Figure 2 Serum phosphorus concentration by weeks of life. Numbers on time axis refers to weeks postnatal. Data within first week postnatal were acquired on the 2nd day after birth. $* P>0.05$.). Serum calcium elevated, while phosphorus had an apparente decline preceding the ascension after birth. Compared with controls, MBD infants had a delay in phosphorus ascension and durative lower phosphorus concentration from the 2nd week after birth. Interestingly, serum calcium got very similar in both groups at the 4th week after birth, and then MBD infants had a sharp down, while controls maintained at stable level. Other demographic and clinical characteristics among cases and controls presented as categorical variables were shown in Table 1.

Univariate logistic regression analyses (Table 2) revealed that, among the putative risk factors evaluated, FGR (OR 6.16, 95\% CI, 2.34-16.20), ELBW (OR 2.49, $95 \% \mathrm{CI}, 1.14-5.41$ ), feeding volume $<80 \mathrm{~mL} / \mathrm{kg} / \mathrm{d}$ at the end of the 4th week after birth (OR 12.95, 95\% CI, 4.8234.84), cholestasis (OR 3.50, 95\% CI, 1.66-7.41), LOS (OR 3.60, 95\% CI, 1.37-9.47) and prolonged (> 2 weeks) diuretics application (OR 5.95, 95\% CI, 1.77-20.05) were all associated with the development of MBD in BPD infants. After adjustment in multiple logistic regression, each remained as statistically significant, independent risk factors (FGR [OR 6.00, 95\% CI, 1.81-19.84], ELBW [OR 3.10, 95\% CI, 1.07-8.94]), feeding volume $<80 \mathrm{~mL} /$ $\mathrm{kg} / \mathrm{d}$ at the end of the 4th week after birth [OR 14.98, 95\% CI, 4.04-55.58], cholestasis [OR 4.44, 95\% CI, 1.5912.40], LOS [OR 3.95, 95\% CI, 1.12-13.98], prolonged diuretics application[OR 5.45, 95\% CI, 1.25-23.84]).

The ratio of different feeding types was not significantly different between the two groups (exclusive breast milk fed $75.0 \%$ vs. $68.3 \%$; partial formula fed $13.5 \%$ vs $21.2 \%$; exclusive formula fed $11.5 \%$ vs $10.6 \%$ in MBD infants and controls respectively; $P=0.508$ ). At the end of the 4th week after birth, MBD infants received a less feeding volume (MBD $107.3 \pm 49.3 \mathrm{ml}$ vs. controls $142.2 \pm 27.8 \mathrm{ml}, P<0.001)$ compared with controls. MBD infants had a delay in time to start fortification [MBD $17(9,30) \mathrm{d}$ vs. controls $9(8,14) \mathrm{d}, P<0.001]$ compared with controls.

No significant difference was found in the need for invasive mechanical ventilation at 36 weeks PMA [MBD $7.7 \%$ vs. controls $1.9 \%, P=0.185$ ], or the length of invasive mechanical ventilation $[\mathrm{MBD} 2(0,14) \mathrm{d}$ vs. controls $1(0,5) \mathrm{d}, P=0.238]$ between the two groups. 


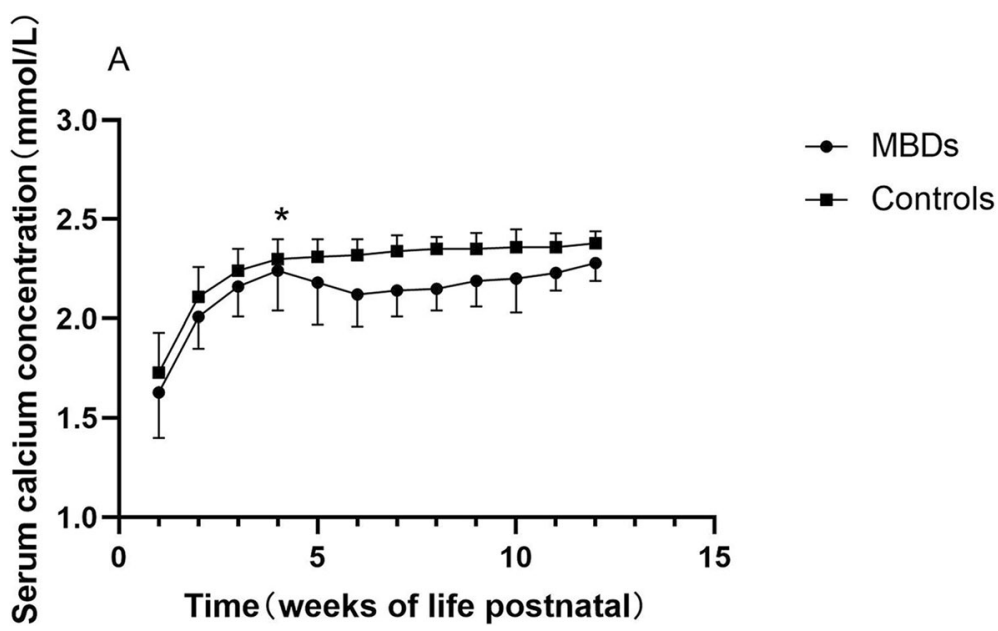

Fig. 1 Serum calcium concentration by weeks of life

\section{Discussion}

The growing advances in the intensive care of preterm infants have led to a decrease in mortality, but caused more frequent morbidity such as MBD and BPD, etc. Previous studies have proved that MBD is inversely associated with gestational age $[4,5]$, hence we matched the gestational age equal to the cases when selecting the controls in order to evaluate other putative factors in homogeneous groups. This study provides novel data on risk factors for MBD in BPD infants. FGR, ELBW (birth weight $<1000 \mathrm{~g}$ ), feeding volume $<80 \mathrm{~mL} / \mathrm{kg} / \mathrm{d}$ at the end of the 4th week after birth, cholestasis and LOS each served as statistically significant, independent risk factors, on the basis of their associated ORs from multiple logistic regression.
The association between FGR and MBD in BPD infants was confirmed in our study which was in accordance with other data published [8]. This early life factor seemed to ease MBD development in a programmed process, which could be used as an early predictive indicator for screening of MBD [17]. FGR commonly coexists with preeclampsia at gestation, resulting in placental abnormalities that deteriorates placental transfer of calcium, magnesium and phosphorus [18]. Furthermore, our study showed that maternal hypertensive disorder without FGR was not associated with MBD, indicating that the disrupted placental function might be the key pathogenesis. In addition to FGR, ELBW was also an independent risk factor for MBD in BPD infants of equal gestational age in our study samples, revealing an inverse

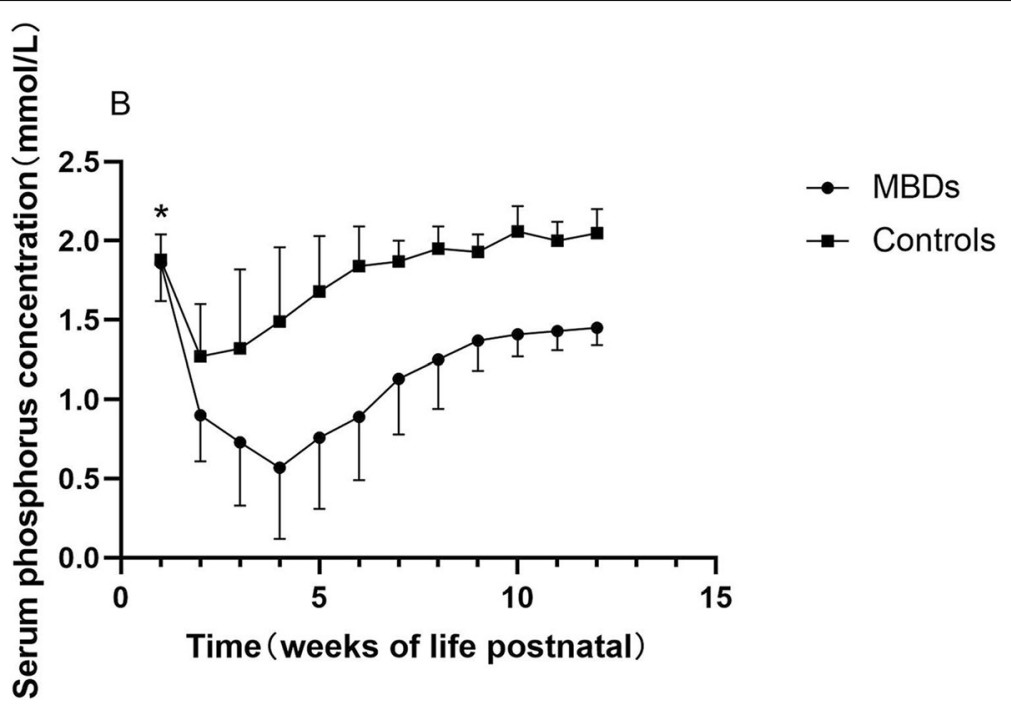

Fig. 2 Serum phosphorus concentration by weeks of life 
Table 1 Demographic and clinical characteristics among cases with MBD and controls

\begin{tabular}{|c|c|c|c|c|}
\hline \multirow{2}{*}{ Antenatal factors } & \multicolumn{2}{|c|}{ Cases } & \multicolumn{2}{|c|}{ Controls } \\
\hline & $n$ & $\%$ & $\mathrm{n}$ & $\%$ \\
\hline & 52 & & 104 & \\
\hline Male & 28 & 53.8 & 52 & 50.0 \\
\hline Steroids & 37 & 71.2 & 79 & 76.0 \\
\hline HCA & 29 & 55.8 & 50 & 48.1 \\
\hline FGR & 16 & 30.8 & 7 & 6.7 \\
\hline Maternal hypertensive disorders without FGR & 5 & 9.6 & 11 & 10.6 \\
\hline PROM & 11 & 21.2 & 27 & 26.0 \\
\hline \multicolumn{5}{|l|}{ Postnatal factors } \\
\hline ELBW & 16 & 30.8 & 17 & 16.3 \\
\hline Exclusive breast milk fed & 39 & 75.0 & 71 & 68.3 \\
\hline Initiation of oral vitamin $D$ supplementation $\geq 2$ weeks after birth & 20 & 38.5 & 26 & 25.0 \\
\hline Feeding volume $<80 \mathrm{~mL} / \mathrm{kg} /$ day at the end of the 4 th week after birth & 23 & 44.2 & 6 & 5.8 \\
\hline NEC & 5 & 9.6 & 4 & 3.8 \\
\hline PDA & 25 & 48.1 & 47 & 45.2 \\
\hline hsPDA & 21 & 40.4 & 35 & 33.7 \\
\hline Cholestasis & 22 & 42.3 & 18 & 17.3 \\
\hline LOS & 12 & 23.1 & 8 & 7.7 \\
\hline Moderate-severe BPD & 31 & 40.4 & 21 & 29.8 \\
\hline Mechanical ventilation & 28 & 53.8 & 57 & 54.8 \\
\hline Mechanical ventilation at 36 PMA & 4 & 7.7 & 2 & 1.9 \\
\hline Dexamethasone & 11 & 21.2 & 14 & 13.5 \\
\hline Diuretics & 16 & 30.8 & 29 & 27.9 \\
\hline Prolonged diuretics ( $>2$ weeks) & 10 & 19.2 & 4 & 3.8 \\
\hline Fluid restriction ( $<140 \mathrm{~mL} / \mathrm{kg}$ beyond 2 weeks after birth) & 13 & 25.0 & 19 & 18.3 \\
\hline Hypothyroidism & 15 & 28.8 & 24 & 23.1 \\
\hline Thrombocytopenia & 9 & 17.3 & 10 & 9.6 \\
\hline
\end{tabular}

MBD, metabolic bone disease; HCA, histologic chorioamnionitis; FGR, fetal growth restriction; PROM, prolonged rupture of membranes; ELBW, extremely low birth weight; NEC, necrotizing enterocolitis; PDA, patent ductus arteriosus; hsPDA, hemodynamically significant PDA; LOS, late onset sepsis; BPD, bronchopulmonary dysplasia; PMA, post-menstrual age

relation between birth weight and MBD, which was found even in ELBWs exclusively by Viswanathan $S$ et al. [19].

Changes in mineral supply, hormonal environment and mechanical stress may cause disrupted bone metabolism after birth. In the early stage, serum calcium can maintain within the optimum range, while phosphorus declined at 1-2 weeks after birth. This could be physiologically and self-limited since infants without MBD took on the same biochemical changes. However, MBD infants presented a longer down period, and lower levels of serum phosphorus and calcium ultimately. Prolonged hypophosphatemia might be more meaningful characteristics and indicator for MBD.

Feeding problems are almost inevitable in the very preterm infants. Generally, it is not difficult to introduce enteral feeding but hard to reach TEN because uncomfortable abdominal distention, gastric retention or signs of NEC usually disrupt the feeding schedule. Prolonged parenteral nutrition (PN) was demonstrated to be associated with $\mathrm{MBD}$ by several research elsewhere [20]. Similarly, our study revealed that an enteral feeding volume $<80 \mathrm{~mL} / \mathrm{kg} / \mathrm{d}$ at the end of the 4 th week after birth remarkably increased the risk for MBD in BPD infants. This may be explained by the following reasons. First, the small feeding volume of breast milk did not allow the introduce of fortifier in our NICU. Even at the usual feeding volume, breast milk did not provide sufficient protein and mineral content to guarantee enough calcium and phosphate intake for preterm infants. Second, the insufficient feeding volume still required PN supplement which posed the possibility of aluminum contamination and the risk of mineral precipitation in the solution due to the small volumes [1]. It has been 
Table 2 Unadjusted OR and aOR for putative risk factors for development of MBD in BPD infants from univariate and multiple logistic regression

\begin{tabular}{|c|c|c|c|c|c|c|c|c|}
\hline \multirow[b]{2}{*}{ Putative risk factors } & \multicolumn{4}{|c|}{ Unadjusted } & \multicolumn{4}{|c|}{ Adjusted } \\
\hline & & $95 \%$ & $95 \%$ & & & $95 \%$ & $95 \%$ & \\
\hline & OR & $\mathrm{LCL}$ & UCL & $P$ & OR & $\mathrm{LCL}$ & $\mathrm{UCL}$ & $P$ \\
\hline \multicolumn{9}{|l|}{ Antenatal factors } \\
\hline Steroids & 0.78 & 0.37 & 1.65 & 0.517 & & & & \\
\hline $\mathrm{HCA}$ & 1.36 & 0.70 & 2.66 & 0.366 & & & & \\
\hline FGR & 6.16 & 2.34 & 16.20 & $<0.001$ & 6.00 & 1.81 & 19.84 & 0.003 \\
\hline Maternal hypertensive disorders without FGR & 0.90 & 0.30 & 2.74 & 0.852 & & & & \\
\hline PROM & 0.77 & 0.35 & 1.70 & 0.765 & & & & \\
\hline \multicolumn{9}{|l|}{ Postnatal factors } \\
\hline ELBW & 2.49 & 1.14 & 5.41 & 0.022 & 3.10 & 1.07 & 8.94 & 0.037 \\
\hline Exclusive breast milk fed & 0.72 & 0.34 & 1.52 & 0.386 & & & & \\
\hline Initiation of oral vitamin $D$ supplementation $\geq 2$ weeks after birth & 1.98 & 0.96 & 4.05 & 0.063 & 1.24 & 0.43 & 3.53 & 0.691 \\
\hline Feeding volume $<80 \mathrm{~mL} / \mathrm{kg} /$ day at the end of the 4 th week after birth & 12.95 & 4.82 & 34.84 & $<0.001$ & 14.98 & 4.04 & 55.58 & $<0.001$ \\
\hline NEC & 2.66 & 0.68 & 10.36 & 0.159 & 0.45 & 0.06 & 3.61 & 0.449 \\
\hline PDA & 1.12 & 0.58 & 2.19 & 0.733 & & & & \\
\hline hsPDA & 1.34 & 0.67 & 2.66 & 0.409 & & & & \\
\hline Cholestasis & 3.50 & 1.66 & 7.41 & 0.001 & 4.44 & 1.59 & 12.40 & 0.004 \\
\hline LOS & 3.60 & 1.37 & 9.47 & 0.009 & 3.95 & 1.12 & 13.98 & 0.033 \\
\hline Dexamethasone & 1.73 & 0.72 & 4.12 & 0.220 & & & & \\
\hline Diuretics & 1.15 & 0.56 & 2.38 & 0.708 & & & & \\
\hline Prolonged diuretics (>2 weeks) & 5.95 & 1.77 & 20.05 & 0.004 & 5.45 & 1.25 & 23.84 & 0.024 \\
\hline Fluid restriction ( $<140 \mathrm{~mL} / \mathrm{kg}$ beyond 2 weeks after birth) & 1.49 & 0.67 & 3.32 & 0.328 & & & & \\
\hline Mechanical ventilation & 0.96 & 0.49 & 1.88 & 0.909 & & & & \\
\hline Hypothyroidism & 1.35 & 0.64 & 2.87 & 0.434 & & & & \\
\hline Thrombocytopenia & 1.97 & 0.75 & 5.20 & 0.172 & 0.75 & 0.15 & 3.84 & 0.729 \\
\hline
\end{tabular}

MBD, metabolic bone disease; BPD, bronchopulmonary dysplasia; HCA, histologic chorioamnionitis; FGR, fetal growth restriction; PROM, prolonged rupture of membranes; ELBW, extremely low birth weight; NEC, necrotizing enterocolitis; PDA, patent ductus arteriosus; hSPDA, hemodynamically significant PDA; LOS, late onset sepsis

demonstrated that newborns fed exclusively with breast milk showed lower levels of phosphate [21] and fortified breast milk feeding significantly increase bone mineral density values via linear regression analysis [22]. Therefore, an earlier begin of fortification of breast milk might be taken into consideration in breast-fed preterm infants with high risk for BPD, as appropriate. Some studies showed that vitamin D supplementation at $>14$ days of age was also associated with MBD, but the results of our study were inconsistent with it. A possible explanation is that it might be the serum 25(OH)D3 that is directly associated with MBD [6]. A usual intake dose of $800-$ $1000 \mathrm{IU} / \mathrm{d}$ for preterm infants with BPD did not achieve the protective level, which is probable due to fat-soluble vitamin deficiency caused by the coexisting cholestasis [23]. Simultaneously, cholestasis was also a risk factor for MBD in BPD infants confirmed by our study and other research [20]. In other words, these infants may be at a greater demand for vitamin D supplementation.

LOS remains one of the most common causes of morbidity and mortality in preterm infants [24]. Jensen EA et al. found that blood culture confirmed sepsis was associated with increased odds of severe MBD in infants with severe BPD [3]. Our study reenforced the association between LOS and MBD in BPD infants. It has been acknowledged that important interactions occur between immune and skeletal systems [25]. Lipopolysaccharide exposures could result in bone loss [26], which might be due to the activation of $\mathrm{B}$ and $\mathrm{T}$ cells that potentially regulate bone resorption [25]. Approaches such as strict hygiene protocol, minimization of invasive interventions and probiotic supplementation in exclusively breast-fed preterm [27] should be employed in prevention of LOS, as promising measures to reduce MBD. 
Diuretics are widely used in NICU with the expectations of improvement in pulmonary mechanics and avoidance of excessive weight gain [28]. However, there are not enough evidence supporting their long-term benefits considering improvement in mortality, duration of mechanical ventilation or oxygen dependence [29]. Furthermore, potential effects of diuretics on bone have been recognized. A single daily dose of loop diuretics (LDs) could increase renal calcium excretion and alter the diurnal rhythm of plasma parathyroid hormone (PTH) levels, and consecutive doses may ultimately result in elevation of circulating PTH and hypophosphatemia [30]. Our study provided an important look at that the duration of LDs therapy in BPD infants was associated with MBD. Orth LE el al also demonstrated that infants exposed to increased cumulative LDs exposure had a higher incidence of MBD and suggested a late diuretic administration initiated after 2 weeks of life [31]. However, serum phosphorus began to decline from 1 to 2 weeks after life, and the declining could last for several weeks. Diuretics usage in this stage might cause adverse effect on mineral metabolism additively. These factors should be considered when making decision to use diuretics in BPD infants.

The strengths of this study are as follows. First, we enrolled only infants with BPD and matched gestational age to ensure the comparison in homogeneous groups. Second, the monocentric study guaranteed that the enrollments were managed strictly under the same perinatal practices including diagnosis and treatments. But there are some limitations. Since MBD is a multifactorial disease, the small sample size may not cover all important risk factors. However, we determine some risk factors that could be interpreted. The results in our study revealed that MBD in BPD infants shared some risk factors the same as preterm infants in general.

\section{Conclusion}

In BPD infants of homogeneous gestational age, FGR, ELBW, feeding volume $<80 \mathrm{~mL} / \mathrm{kg} / \mathrm{d}$ at the end of the 4th week after birth, cholestasis, LOS and prolonged (> 2 weeks) diuretics application are significant risk factors for MBD. Given the observational nature of this study, further longitudinal/prospective studies are required to validate these findings.

\footnotetext{
Abbreviations

MBD: Metabolic bone disease; BPD: Bronchopulmonary dysplasia; HCA: Histologic chorioamnionitis; FGR: Fetal growth restriction; ELBW: Extremely low birth weight; VLBW: Very low birth weight; PROM: Prolonged rupture of membranes; PDA: Patent ductus arteriosus; hsPDA: Hemodynamically significant PDA; NEC: Necrotizing enterocolitis; LOS: Late onset sepsis; ALP: Alkaline phosphatase; PTH: Parathyroid hormone; PLT: Platelet; LDs: Loop diuretics; PMA: Post-menstrual age; TEN: Total enteral nutrition; PN: Parenteral nutrition; NICU: Neonatal intensive care unit; OR: Odds ratio; aOR: Adjusted odds ratio; Cl: Confidence interval
}

\section{Acknowledgements}

This work was completed at the Department of Neonatology, Zhangzhou Hospital Affiliated to Fujian Medical University. The authors thank all colleagues for their help in the process.

\begin{abstract}
Authors' contributions
XLP had primary responsibility for the study design and protocol development. CWW performed the final data analyses and contributed to the writing of the manuscript. ZZH was involved in the data collection. DSZ was involved in the table drawing. All authors read and approved the final manuscript.
\end{abstract}

\section{Funding}

The study was supported by Startup Fund for scientific research of Fujian Medical University (no.2019QH1270). The funders were not involved in the study design, data collection, analysis, interpretation, or manuscript preparation

\section{Availability of data and materials}

The datasets used and/or analyzed during the current study are available from the corresponding author on reasonable request.

\section{Declarations}

\section{Ethics approval and consent to participate}

The study was approved by the Institutional Ethical Committee of the Zhangzhou Hospital. The study was based on register data, and individual informed consent from each participant is not required by waiver from the Ethical Committee and national guidelines. All the patient-related information was anonymized. The Hospital Institution authorized the administrative permission to the study team to access the data for research purpose on the nature of public health.

\section{Consent for publication}

Not applicable.

\section{Competing interests}

None declared.

Received: 3 October 2020 Accepted: 6 May 2021

Published online: 17 May 2021

\section{References}

1. Faienza MF, D'Amato E, Natale MP, Grano M, Chiarito M, Brunetti G, et al. Metabolic bone disease of prematurity: diagnosis and management. Front Pediatr. 2019; 7: 143. doi: https://doi.org/10.3389/fped.2019.00143. PMID: 31032241; PMCID: PMC6474071.

2. Gaio P, Verlato G, Daverio M, Cavicchiolo ME, Nardo D, Pasinato A, de Terlizzi F, Baraldi E Incidence of metabolic bone disease in preterm infants of birth weight $<1250 \mathrm{~g}$ and in those suffering from bronchopulmonary dysplasia. Clin Nutr ESPEN 2018; 23: 234-239. doi: https://doi.org/10.1016/j. clnesp.2017.09.008. PMID: 29460805.

3. Jensen EA, White AM, Liu P, Yee K, Waber B, Monk HM, Zhang H Determinants of severe metabolic bone disease in very low-birth-weight infants with severe Bronchopulmonary dysplasia admitted to a tertiary referral center. Am J Perinatol 2016; 33(1): 107-113. doi: https://doi.org/10.1 055/s-0035-1560043. PMID: 26295968.

4. Costa R, Franco C, Santos N, Maio P, Vieira F, Antunes S, et al. Metabolic bone disease of prematurity in very low birthweight infants: retrospective observational study. Acta Med Port. 2019; 32(7-8): 536-541. doi: https://doi. org/10.20344/amp.10994. PMID: 31445534.

5. Chen W, Yang C, Chen H, Zhang B. Risk factors analysis and prevention of metabolic bone disease of prematurity. Medicine (Baltimore). 2018; 97(42): e12861. doi: https://doi.org/10.1097/MD.0000000000012861. PMID: 30334994; PMCID: PMC6211899.

6. Montaner Ramón A, Fernández Espuelas C, Calmarza Calmarza P, Rite Gracia S, Oliván Del Cacho MJ. Risk factors and biochemical markers in metabolic bone disease of premature newborns. Rev Chil Pediatr 2017; 88(4): 487-494. doi: https://doi.org/10.4067/S0370-41062017000400007. PMID: 28898316. 
7. Ukarapong S, Venkatarayappa SKB, Navarrete C, Berkovitz G. Risk factors of metabolic bone disease of prematurity. Early Hum Dev 2017; 112:29-34. doi: https://doi.org/10.1016/j.earlhumdev.2017.06.010. PMID: 28683339.

8. Higgins RD, Jobe AH, Koso-Thomas M, Bancalari E, Viscardi RM, Hartert TV, et al. Bronchopulmonary dysplasia: executive summary of a workshop. J Pediatr. 2018; 197:300-308. doi: https://doi.org/10.1016/j.jpeds.2018.01.043. PMID: 29551318; PMCID: PMC5970962.

9. Backström MC, Kouri T, Kuusela AL, Sievänen H, Koivisto AM, Ikonen RS, Mäki M Bone isoenzyme of serum alkaline phosphatase and serum inorganic phosphate in metabolic bone disease of prematurity. Acta Paediatr 2000; 89(7): 867-873. PMID: 10943972, DOI: https://doi.org/10.1111/ j.1651-2227.2000.tb00395.x.

10. Torchin H, Lorthe E, Goffinet F, Kayem G, Subtil D, Truffert P, et al. Histologic chorioamnionitis and bronchopulmonary dysplasia in preterm infants: the epidemiologic study on low gestational ages 2 cohort. J Pediatr. 2017; 187: 98-104.e3. doi: https://doi.org/10.1016/j.jpeds.2017.05.019. PMID: 28583707

11. Salvador A, Janeczko M, Porat R, Sekhon R, Moewes A, Schutzman D. Randomized controlled trial of early parenteral nutrition cycling to prevent cholestasis in very low birth weight infants. J Pediatr. 2012; 161(2): 229-233. e1. doi: https://doi.org/10.1016/j.jpeds.2012.02.003. PMID: 22424948.

12. Leeman L, Dresang LT, Fontaine P. Hypertensive disorders of pregnancy. Am Fam Physician 2016; 93(2): 121-127. PMID: 26926408.

13. Kahveci H, Tayman C, Laloğlu F, Kavas N, Ciftel M, Yılmaz O, et al. Relationship between hemodynamically significant ductus arteriosus and ischemia-modified albumin in premature infants. Indian J Clin Biochem. 2016; 31(2): 231-236. doi: https://doi.org/10.1007/s12291-015-0523-z. PMCID: PMC4820428.

14. Hashemipour M, Hovsepian S, Ansari A, Keikha M, Khalighinejad P, Niknam N. Screening of congenital hypothyroidism in preterm, low birth weight and very low birth weight neonates: a systematic review. Pediatr Neonato 2018; 59(1): 3-14. doi: https://doi.org/10.1016/j.pedneo.2017.04.006. PMID: 28811e156

15. Kulkarni W, Dutta S, Sundaram V, Saini SS. Preterm thrombocytopenia and delay of Ductus Arteriosus closure. Pediatrics. 2016; 138(4): e20161627. doi: https://doi.org/10.1542/peds.2016-1627. PMID: 27681010.

16. Alcock G, Liley HG, Cooke L, Gray PH. Prevention of neonatal late-onset sepsis: a randomised controlled trial. BMC Pediatr. 2017; 17(1): 98. doi: https://doi.org/10.1186/s12887-017-0855-3. PMID: 28376891; PMCID: PMC5381090.

17. Wood CL, Wood AM, Harker C, Embleton ND. Bone mineral density and osteoporosis after preterm birth: the role of early life factors and nutrition. Int J Endocrinol. 2013; 2013: 902513. doi: https://doi.org/10.1155/2013/902 513. PMID: 23662104; PMCID: PMC3639624.

18. Lager S, Sovio U, Eddershaw E, van der Linden MW, Yazar C, Cook E, et al. Abnormal placental CD8+ T-cell infiltration is a feature of fetal growth restriction and pre-eclampsia. J Physiol. 2020;598(23):5555-71. 32886802. https://doi.org/10.1113/JP279532.

19. Viswanathan S, Khasawneh W, McNelis K, Dykstra C, Amstadt R, Super DM, Groh-Wargo S, Kumar D Metabolic bone disease: a continued challenge in extremely low birth weight infants. JPEN J Parenter Enteral Nutr 2014; 38(8): 982-990. doi: https://doi.org/10.1177/0148607113499590. PMID: 23963689.

20. Lee SM, Namgung R, Park MS, Eun HS, Park KI, Lee C. High incidence of rickets in extremely low birth weight infants with severe parenteral nutrition-associated cholestasis and bronchopulmonary dysplasia. J Korean Med Sci. 2012; 27(12): 1552-1555. doi: https://doi.org/10.3346/jkms.2012.2 7.12.1552. PMID: 23255857; PMCID: PMC3524437.

21. Bandara S, Kariyawasam A. Incidence of osteopenia of prematurity in preterm infants who were exclusively fed breast milk. Early Hum Dev. 2010; 86:S18. https://doi.org/10.1016/j.earlhumdev.2010.09.053.

22. Figueras-Aloy J, Álvarez-Domínguez E, Pérez-Fernández JM, MoretonesSuñol G, Vidal-Sicart S, Botet-Mussons F. Metabolic bone disease and bone mineral density in very preterm infants. J Pediatr 2014; 164(3): 499-504. doi: https://doi.org/10.1016/j.jpeds.2013.10.089. PMID: 24331689.

23. Samra NM, Emad El Abrak S, El Dash HH, El Said El Raziky M, El Sheikh MA. Evaluation of vitamin D status bone mineral density and dental health in children with cholestasis. Clin Res Hepatol Gastroenterol 2018; 42(4): 368377. doi: https://doi.org/10.1016/j.clinre.2017.11.010. PMID: 29551613.

24. Stoll BJ, Hansen N, Fanaroff AA, Wright LL, Carlo WA, Ehrenkranz RA, Lemons JA, Donovan EF, Stark AR, Tyson JE, Oh. W, Bauer CR, Korones SB, Shankaran S, Laptook AR, Stevenson DK, Papile LA, Poole WK Late-onset sepsis in very low birth weight neonates: the experience of the NICHD neonatal research network. Pediatrics. 2002; 110 (2 Pt 1): 285-291. doi: https://doi.org/10.1542/peds.110.2.285. PMID: 12165580.

25. Horowitz MC, Fretz JA, Lorenzo JA. How B cells influence bone biology in health and disease. Bone. 2010; 47(3): 472-479. doi: https://doi.org/10.1016/j. bone.2010.06.011. PMID: 20601290; PMCID: PMC2941392.

26. Dusad A, Thiele GM, Klassen LW, Gleason AM, Bauer C, Mikuls TR, et al. Organic dust, lipopolysaccharide, and peptidoglycan inhalant exposures result in bone loss/disease. Am J Respir Cell Mol Biol. 2013; 49(5): 829-836. doi: https://doi.org/10.1165/rcmb.2013-01780C. PMID: 23782057; PMCID: PMC3931104.

27. Aceti A, Maggio L, Beghetti I, Gori D, Barone G, Callegari ML, et al. Probiotics prevent late-onset sepsis in human milk-fed, very low birth weight preterm infants: systematic review and meta-analysis. Nutrients. 2017; 9(8): 904. doi: https://doi.org/10.3390/nu9080904. PMID: 28829405; PMCID: PMC5579697.

28. Hagadorn JI, Sanders MR, Staves C, Herson VC, Daigle K. Diuretics for very low birth weight infants in the first 28 days: a survey of the U.S. neonatologists. J Perinatol 2011; 31(10): 677-681. doi: https://doi.org/10.103 8/jp.2011.11. PMID: 21394079

29. Stewart A, Brion LP, Soll R. Diuretics for respiratory distress syndrome in preterm infants. Cochrane Database Syst Rev. 2011; 2011(12): CD001454. doi: https://doi.org/10.1002/14651858.CD001454.pub3. PMID: 22161366; PMCID: PMC7055205.

30. Rejnmark L, Vestergaard P, Heickendorff L, Andreasen F, Mosekilde L. Loop diuretics increase bone turnover and decrease BMD in osteopenic postmenopausal women: results from a randomized controlled study with bumetanide. J Bone Miner Res 2006; 21(1): 163-170. doi: https://doi.org/1 0.1359/JBMR.051003. PMID: 16355285.

31. Orth LE, O'Mara KL. Impact of early versus late diuretic exposure on metabolic bone disease and growth in premature neonates. J Pediatr Pharmacol Ther. 2018; 23(1): 26-33. doi: https://doi.org/10.5863/15516776-23.1.26. PMID: 29491749; PMCID: PMC5823489.

\section{Publisher's Note}

Springer Nature remains neutral with regard to jurisdictional claims in published maps and institutional affiliations.

\section{Ready to submit your research? Choose BMC and benefit from:}

- fast, convenient online submission

- thorough peer review by experienced researchers in your field

- rapid publication on acceptance

- support for research data, including large and complex data types

- gold Open Access which fosters wider collaboration and increased citations

- maximum visibility for your research: over $100 \mathrm{M}$ website views per year

At BMC, research is always in progress.

Learn more biomedcentral.com/submissions 